\title{
Em tempos de guerra e de paz: a Educação Especial em Angola
}

\author{
In times of war and peace: Special Education in Angola
}

En tiempos de guerra y de paz: la Educación Especial en Angola

\section{* Daniela Antonello Lobo D'avila}

Doutora pela Universidade de Brasília, Brasília, Distrito Federal, Brasil. danielalobodavila@gmail.com - https://orcid.org/0000-0003-2778-1532

\section{** Selma Alves Pantoja}

Professora doutora na Universidade de Brasília, Brasília, Distrito Federal, Brasil. selmaunb@gmail.com - https://orcid.org/0000-0002-5234-2753

\section{*** Paulo de Carvalho}

Professor Catedrático na Universidade Agostinho Neto, Luanda, Angola, Brasil. paulodecarvalho@hotmail.com

Recebido em 08 de maio de 2018

Aprovado em 16 de julho de 2019

Publicado em 12 de setembro de 2019

\section{RESUMO}

Este estudo investiga a construção das políticas educacionais voltadas à Educação Especial no Sistema Educacional de Ensino (SEE) angolano. A análise parte da inexistência dessa política desde o regime colonial às iniciativas constituídas a partir da independência do país tanto nos períodos de guerra civil como em tempos de paz. Analisa-se a trajetória do ensino especial tendo por fonte os documentos oficiais do governo angolano com o intuito de identificar os significados das formulações em relação à conjuntura política $e$ econômica nos diferentes momentos da história do país. Metodologicamente, trata-se de pesquisa qualitativa, na qual os documentos oficiais são analisados sob a ótica da análise crítica do discurso. A temática do ensino especial foi contemplada no âmbito dos aspectos normativos institucionais durante a I e a II República, caracterizando marcos históricos à compreensão dos rumos da Educação Especial. Contudo, o desenvolvimento educacional em meio à instabilidade política e econômica devido à guerra civil fragilizou a implementação das políticas de Educação Especial. Com a instauração da paz, o governo angolano investiu na elaboração e aprovação de documentos e legislações voltados ao ensino especial e registrou, nos doze anos do pós-guerra (2002-2014), um aumento expressivo de $284 \%$ dos alunos da Educação Especial matriculados. Pode-se afirmar que a efetiva implementação da Educação Especial ocorre com o fim da guerra civil, com a formação de professores, com a aprovação de políticas públicas e a influência advinda de parcerias com as agências das Nações Unidas, além de cooperações técnicas com o chamado Sul Global. 
Palavras-chave: Angola; Educação Especial; Política educacional.

\section{ABSTRACT}

This study investigates the construction of educational policies focused on Special Education in the Angolan Education System (ESS). The analysis starts from the absence of this policy from the colonial regime to the initiatives constituted from the independence of the country in both periods of civil war and times of peace. The trajectory of special education is analyzed as a source of the official documents of the Angolan government in order to identify the meanings of the formulations in relation to the political and economic conjuncture. Methodologically, this is a qualitative research, in which the official documents are analyzed from the point of view of the critical analysis of the discourse. The theme of special education was contemplated within the scope of institutional normative aspects during the First and Second Republics, characterizing historical milestones to understand the directions of Special Education. However, educational development amid political and economic instability due to civil war has weakened the implementation of Special Education policies. With the establishment of peace, the government invested in the elaboration and approval of documents and legislation aimed at special education and recorded, after the war (2002-2014), an expressive increase of $284 \%$ of Special Education students enrolled. It can be affirmed that the effective implementation of Special Education takes place with the end of the civil war, with teacher training, with the approval of public policies and the influence of partnerships with UN agencies, as well as technical cooperation with the called Global South.

Keywords: Angola; Special Education; Educational politics.

\section{RESUMEN}

Este estudio investiga la construcción de las políticas educativas dirigidas a la Educación Especial en el Sistema Educativo de Enseñanza angoleño. Se analiza la trayectoria de la enseñanza especial teniendo por fuente los documentos oficiales del gobierno angoleño con el propósito de identificar los significados de las formulaciones en relación a la coyuntura política y económica en los diferentes momentos de la historia del país. Metodológicamente, se trata de una investigación cualitativa, en la cual los documentos oficiales son analizados bajo la óptica del análisis crítico del discurso. La temática de la enseñanza especial fue contemplada en el marco de los aspectos normativos institucionales durante la I y la II República, caracterizando marcos históricos a la comprensión de los rumbos de la Educación Especial. Sin embargo, el desarrollo educativo en medio de la inestabilidad política y económica debido a la guerra civil ha debilitado la implementación de las políticas de Educación Especial. Con la instauración de la paz, el gobierno angoleño invirtió en la elaboración y aprobación de documentos y legislaciones orientados a la enseñanza especial y registró, en los doce años de la posguerra, un aumento expresivo del $284 \%$ de los alumnos de Educación Especial matriculados. Se puede afirmar que la efectiva implementación de la Educación Especial ocurre con el fin de la guerra civil, con la formación de profesores, con la aprobación de políticas públicas y la influencia proveniente de alianzas con las agencias de las Naciones Unidas, además de cooperaciones técnicas con el gobierno llamado Sur Global. 
Palabras clave: Angola; Educación Especial; Política educativa.

\section{Introdução}

Este estudo investiga a construção das políticas educacionais voltadas à Educação Especial no Sistema Educacional de Ensino angolano, desde a sua invisibilidade caracterizada no regime colonial às iniciativas de visibilidade constituídas a partir da independência do país e nos períodos instituídos pela guerra civil e em tempos de paz. Analisamos a criação e ampliação das legislações governamentais específicas à área da Educação Especial, a abertura política no âmbito da cooperação internacional e as mudanças de paradigmas acerca da participação dos alunos sujeitos da Educação Especial no sistema de ensino angolano à luz de cada momento histórico.

Os estudos realizados no âmbito da educação em Angola, contemplados nas pesquisas de Zau (2002, 2009), Liberato (2014), Nguluve (2010), Vieira (2007), Matos (1998), Mbemba (1998), Paxe (2014), entre outros, oferecem amplas reflexões críticas sobre a implementação do Sistema de Educação e Ensino (SEE) no país em questão, principalmente, a partir da independência. Dentre esses autores/as, apenas Zau, Matos e Paxe analisam alguns aspectos sobre o ensino especial tendo como fonte de dados os documentos oficiais do governo angolano e somente em alguns períodos determinados da história.

Contudo, a produção bibliográfica referente ao ensino especial em Angola e os desafios impostos à sua implementação na rede de ensino, caracterizados tanto no ensino de base geral quanto nas escolas especiais, ainda é incipiente. Não há análises que retratem a memória histórica da implementação das políticas de inclusão compreendidas criticamente no decorrer de 41 anos de independência do país e o que essa trajetória política e institucional representa às pessoas com deficiência na sociedade angolana.

Diante do exposto, salienta-se que o presente estudo se justifica como subsídio à compreensão das atuais políticas educacionais de inclusão em Angola, fortalecidas pelos movimentos sociais e ratificada pelo governo angolano aos documentos internacionais (ONU, 2006; CUA, 2009).

Este estudo é resultado da pesquisa de campo realizada em Angola no ano de 2016, que compreendeu também a observação direta e a entrevista em profundidade (BEAUD e WEBER, 2007; JACCOUD e MAYER, 2008) com trinta famílias que têm filhos e filhas com 
deficiência e dez profissionais e gestores que atuam na área do ensino especial. Neste artigo, buscamos aprofundar a análise da trajetória do ensino especial em Angola, tendo por fonte de dados os documentos oficiais do governo angolano referentes a temática, com o intuito de identificar os significados das formulações sobre a Educação Especial em relação à conjuntura política e econômica dados os diferentes momentos da história do país, além das relações políticas estabelecidas com organismos internacionais e as implicações dessa hibridização para a Educação Especial em Angola. Metodologicamente, trata-se de pesquisa qualitativa, na qual os documentos oficiais são analisados sob a ótica da análise crítica do discurso (CELLARD, 2008).

Para tanto, este estudo foi dividido em três seções, além desta introdução e considerações finais. A primeira seção discorre sobre as ações governamentais pósindependência que embasaram os investimentos e os rumos conceituais do ensino especial em Angola durante os anos de 1975 a 1991, período denominado como I República, a qual reivindicava uma perspectiva educacional fundamentada no legado socialista. A segunda seção aborda a constituição da Educação Especial com o reacender da guerra civil, de 1991 a 2001, denominado como II República, e os desafios enfrentados no setor educacional para a implementação do ensino especial em tempos de guerra. A terceira seção contempla o cenário da Educação Especial em tempos de paz, com o calar das armas a partir do ano de 2002 aos dias atuais. Nessa seção, a análise é norteada pela perspectiva da reconciliação nacional, pela expansão do ensino especial com o fortalecimento de políticas públicas e pela inserção do país no cenário mundial acerca da discussão dos temas relativos à pessoa com deficiência com vistas à implementação de uma política educacional na perspectiva da educação inclusiva.

\section{Educação Especial em tempo do nascimento da nação}

O legado autoritário e excludente do regime colonial em Angola retrata os séculos de negligência ao processo educacional das pessoas com deficiência, uma vez que o sistema educativo colonial não contemplava a Educação Especial na sua estrutura escolar, nem mesmo em atendimentos específicos e/ou segregados. A única e pontual iniciativa registrada foi em 1972, com a tímida admissão de dez alunos com deficiência visual na escola Óscar Ribas (em Luanda), com ênfase na habilitação e reabilitação desses sujeitos à área profissional (ANGOLA, 2006). Esse fato, que ocorre apenas três anos antes da Independência do país, demonstra o amplo descaso do regime colonial para com as 
pessoas com deficiência, o que fortaleceu a exclusão social e educacional dos mesmos na sociedade angolana.

Os anos de 1975 a 1991, caracterizados com a Primeira República, consagraram-se por meio da conquista da Independência, da centralização econômica, do monopartidarismo, dos fundamentos socialistas e do legado Constitucional de 1975, que previa um Estado soberano, independente, democrático e livre dos resquícios de qualquer forma de exploração (ANGOLA, 1975).

Para reverter o cenário de exclusão educacional herdados na colonização, o governo angolano, representado pelo Comitê Central do Movimento Popular de Libertação de Angola/MPLA, inspirou-se nos princípios da Revolução Cubana e instituiu, no ano de 1976, a Lei de Nacionalização do Ensino a fim de promover a gratuidade do ensino, eliminar o analfabetismo e consolidar a consciência nacional em Angola (CARVALHO FILHO, 2016). Isso refletia a vontade de iniciar um ciclo de mudanças sociais e de desenvolvimento para o país, no qual previa-se subverter a sociedade colonial e elaborar um discurso nacional para a construção do que se chamou de um 'homem novo', em uma referência às mudanças culturais pretendidas (PANTOJA, 2016). Contudo, o tão esperado desenvolvimento teve de ser gerido em meio ao desafio da guerra civil e do contexto de instabilidade política que exauriam quase todos recursos financeiros e dificultavam a autonomia econômica do setor educacional para conduzir a melhoria das escolas e a formação de professores (ZAU, 2002; LIBERATO, 2014).

Mesmo diante desses desafios, o Ministério da Educação constituiu em 1977 o Sistema de Educação e Ensino (SEE), fundamentado na concepção de uma educação autointitulada como "revolucionária e marxista", cujos preceitos seriam a igualdade de oportunidades no acesso aos estudos, a gratuidade do ensino em todos os níveis, bem como o aperfeiçoamento dos docentes (ZAU, 2009; VIEIRA, 2007; ANGOLA, 2003a). A elaboração de uma nova proposta ao ensino para uma Angola independente mobilizou profissionais angolanos e estrangeiros de diferentes áreas do conhecimento com o intuito de concretizar o objetivo de uma educação pública à população angolana que ficou fora do sistema de ensino durante o período colonial (FREUDENTHAL, 2000), incluindo as pessoas com deficiência.

A iniciativa do governo angolano gerou, após dois anos da Independência, o aumento expressivo de 1.026.291 matrículas de estudantes africanos no sistema educacional, 
distribuídas em 15 províncias (ZAU, 2002). Havia, no entanto, uma necessidade maior de profissionais habilitados para a imensa tarefa que foi assumida pelo governo angolano, uma vez que a maioria dos professores portugueses abandonaram Angola com a independência e os professores angolanos com formação adequada eram escassos (NETO, 2012; FREUDENTHAL, 2000). Essas dificuldades geravam a necessidade de realizar parcerias com Organismos Internacionais na mediação da formação docente.

O princípio de cooperação internacional de países e profissionais que comungavam as ideias socialistas foi força motriz da estruturação do sistema de ensino angolano, bem como as intervenções do Programa das Nações Unidas para o Desenvolvimento/PNUD e outras ações que envolviam as Nações Unidas, com Missões e os poucos professores tentando construir uma nova proposta de educação autodefinida como revolucionária. Segundo Mbemba (1998) a relação de cooperação entre Angola e a Unesco teve início em 1976 com a admissão de Angola como Estado membro, e nesse mesmo ano desenvolveuse o projeto de "formação de formadores do ensino de base e sobre o desenvolvimento das línguas nacionais", ambos financiados pelo PNUD.

É nesse contexto que se identifica a primeira iniciativa do governo angolano em contemplar o ensino especial na nova estrutura organizacional do SEE de 1977. Essa estrutura fora constituída por Instituições educativas pré-escolares; Escolas do ensino de base; Institutos de ensino médio; Institutos de ensino superior; Escolas especiais e estabelecimentos para crianças deficientes; e Instituições para a instrução de adultos e aperfeiçoamento profissional (ZAU, 2002). De acordo com este autor, a proposta estipulada para a Educação Especial tinha a seguinte determinação:

Este tipo de escolas e de estabelecimentos de ensino tinha como função
fundamental, possibilitar a aquisição da instrução de base, geral e
profissional, às crianças e jovens deficientes de vários tipos e graus,
tornando-as assim capazes para o trabalho ou para a vida autónoma. A
educação e a instrução das crianças, que se encontrassem nestas condições
de diminuídos, seria organizada nas Instituições pré-escolares, escolares e
outras apropriadas para estes fins, nas escolas especiais ou nas secções que
viessem a existir no quadro da Escola de Base Regular e/ou nas Instituições
de Saúde sociais correspondentes (ZAU, 2002, p.125).

Apesar da estrutura educacional prever a construção de escolas especiais e estabelecimentos para crianças deficientes, neste momento elas ainda eram ausentes. Devido a isso, a responsabilidade pela educação e instrução de "crianças e jovens deficientes" se daria nas Instituições pré-escolares, escolares e outras apropriadas para estes fins. O que demonstrava que mesmo sem a escola especial, se considerava iniciar o 
processo de aprendizagem no ensino regular junto com todos os estudantes com ou sem deficiência, caracterizando um marco institucional para com a educação de pessoas historicamente excluídas da vida pública em Angola. Concretamente, esses estudantes não foram matriculados no sistema regular de ensino neste momento da história de Angola, apesar da letra da lei, por um conjunto de motivos que serão explorados mais a frente neste texto, mas o texto constitucional constituiu o princípio do diálogo governamental sobre a inserção desses sujeitos no sistema de ensino junto com os demais alunos.

A estrutura educacional proposta pelo SEE de 1977 ainda previa que as escolas especiais fossem criadas para oferecer instrução técnica e formação profissional aos jovens com deficiência após a escolarização da escola de ensino regular. Isso incluía a previsão de estabelecimentos especiais organizados, sob forma de internato para que os jovens que tivessem finalizado a formação da escola especial pudessem continuar a qualificação de suas capacidades para o mundo do trabalho com formações mais específicas (ZAU, 2002, 2009).

Mediante essas descrições, arriscamos considerar que a proposta teórica do SEE de 1977 contemplou o ensino às pessoas com deficiência na educação pré-escolar e escolar no ensino regular de base geral junto com todos os estudantes. Assim como, apoiou o ensino técnico e a formação profissional em escolas especializadas que contemplassem as especificidades dos educandos, com oferecimento de apoio a moradia (internatos), para que esses estudantes pudessem ter condições de permanecerem nos locais de estudo e finalizarem suas formações profissionais.

Por um lado, assistia-se à tentativa de organização educacional na busca de alternativas para proporcionar educação a todos os cidadãos angolanos. Por outro lado, o contexto social e político ficava cada vez mais complexo e impetuoso no decorrer da década de 1970 e início de 1980, consumado com a intensificação da guerra civil que atingiu grande parte do território angolano, com ênfase nas regiões rurais e áreas de acesso urbano em cidades estrategicamente importantes (CARVALHO, 2002). Com isso, as propostas até então realizadas na área da Educação Especial ficaram circunscritas apenas às regiões não afetadas pela guerra, sendo fortalecidas principalmente no âmbito da capital do país, uma vez que as decisões políticas e educacionais eram centralizadas em Luanda por uma série de fatores, que incluíam primordialmente uma maior segurança em relação ao conflito armado. 
A efetiva implementação da Educação Especial se deu por meio da Circular ㄲo 56 de 1979, que criou as condições mínimas indispensáveis para colocar em funcionamento as escolas de Educação Especial, como modalidade de ensino específica (ANGOLA, 2006). Esse marco institucional conduziu à ampliação do diálogo sobre a visibilidade das pessoas com necessidades educativas especiais no contexto escolar, incluindo ainda questões que englobavam as deficiências adquiridas no contexto da guerra antes e após a independência.

Com a implementação das escolas especiais, pressupõe-se que a escolarização desse público alvo deveria ser realizada primordialmente neste âmbito, por ofertarem um atendimento especial às necessidades individualizadas dos estudantes, ou seja, com enfoque na deficiência. Em outras palavras, seria uma escola na qual apenas os estudantes que apresentassem alguma deficiência fariam parte. Todavia, ambas orientações educacionais estavam vigentes, dando a possibilidade de investimentos tanto à proposta educacional do SEE de 1977, quanto à orientação da Circular no56.

Dois anos após a implementação da Circular nํ56, foi criado o Departamento Nacional para a Educação Especial (Decreto ํㅡ0/1981). Esse decreto orientava as escolas especiais e as salas especiais ${ }^{1}$ (abertas nesse período) a desenvolverem um trabalho voltado para a deficiência visual, auditiva e posteriormente intelectual. Esse atendimento caracterizou-se por proporcionar um trabalho centrado na deficiência em ambientes escolares segregados, o que segundo a perspectiva na época significou um avanço no quesito de política educacional para esse público, uma vez que até esse momento as crianças com deficiência não tinham acesso a nenhum tipo de equipamento ou recursos específicos para suas necessidades (ANGOLA, 2015). Sendo assim, houve o entendimento que um espaço mais segregado das escolas especiais e/ou salas especiais facilitaria o uso de recursos mais específicos a cada deficiência e consequentemente os estudantes com necessidades educacionais especiais aprenderiam com mais facilidade.

Em síntese, consideramos que a temática da Educação Especial foi contemplada no âmbito dos aspectos normativos institucionais durante os doze anos da I República,

\footnotetext{
${ }^{1}$ As salas especiais são compreendidas por turmas constituídas apenas por estudantes sujeitos do ensino especial, essas salas segregadas estão alocadas dentro das escolas regulares. As escolas especiais caracterizam-se pelo atendimento exclusivo dos estudantes com necessidades educativas especiais em ambiente separado das escolas regulares de ensino, ou seja, possuem local próprio caracterizado pelo ensino especializado.
} 
caracterizando marcos históricos fundamentais à compreensão dos investimentos institucionais e os rumos conceituais e paradigmáticos da Educação Especial. Todavia muitos foram os fatores que contribuíram para dificultar a implementação das propostas do ensino especial durante a I República, nos quais incluímos a omissão do regime colonial para com o ensino especial gerando um ciclo vicioso de invisibilidade e exclusão social (em todos os domínios sociais) que contribuíram na reprodução das representações sociais em torno da deficiência baseadas em preconceitos, estigmas e mitos. Outro obstáculo se constituiu já com a nova proposta educacional do governo angolano no pós-independência a qual estreou a tão esperada utopia do desenvolvimento educacional em meio à instabilidade política e econômica conduzidas pelas consequências da guerra civil, o que fragilizou a implementação da Educação Especial no âmbito do SEE, dentre as quais mencionamos a ausência de profissionais com formação específica na área da Educação Especial; a ausência de modelos educacionais voltados ao ensino especial; os escassos recursos e investimentos no que se refere a estrutura física, materiais e recursos específicos à aprendizagem dos estudantes com deficiência e a constante ampliação do número de pessoas com deficiência provocada pela guerra.

\section{Educação Especial com o reacender da guerra}

Com a abertura do país ao multipartidarismo e ao processo de democratização que inicia com a II República em 1991, acontecem importantes mudanças estruturais e ideológicas a partir da Lei oㅜ 12/1991, que são complementadas com a Lei de Revisão Constitucional no 23/1992. Dentre as mudanças organizacionais no sistema político e econômico o país se vê substituindo os supostos objetivos socialistas e ideais marxistas para imergir numa perspectiva capitalista veiculada à globalização (ZAU, 2002, 2009). Para Nguvule (2010) os novos desafios sociais exigiam mudanças no sistema de ensino que contemplassem os princípios da democracia e da liberdade política, uma vez que esse sistema estava baseado na ideologia do MPLA, enquanto partido único (monopartidarismo).

A reformulação do SEE, aprovada em 1988 e vigente em 1992, incidiu em modificações organizacionais e estruturais ${ }^{2}$, incluindo a área do ensino especial, a

\footnotetext{
${ }^{2}$ A estrutura organizacional do sistema educacional passou a integrar as seguintes categorias: Subsistema do Ensino Geral; Subsistema da Formação de Professores; Subsistema do Ensino de Adultos; Subsistema do ensino Técnico-profissional e Subsistema do Ensino Superior (ANGOLA, 2003b; ZAU, 2002).
} 
qual passou a ser uma modalidade especial de ensino dentro do Subsistema do Ensino Geral (níveis primário e secundário), compreendendo os níveis primário e secundário, com vistas a recuperação e a integração socioeducativa dos indivíduos com necessidades educativas específicas (ZAU, 2002).

Com a revisão do SEE, o ensino especial integra-se no Ensino Geral (escolas regulares) como uma modalidade especial de Ensino, no qual sublinha o entendimento de que a aprendizagem dos alunos da Educação Especial, se daria conjuntamente com outros alunos no mesmo ambiente das escolas regulares do Ensino Geral primário e secundário, mantendo com isso a base dos princípios que já haviam sido estipulados na primeira versão do SEE/1977. Em suma, as alterações do SEE no que tange ao ensino especial mantiveram a proposta de 'integração' no ensino geral (primário e secundário), porém suprimiram as propostas voltadas ao ensino técnico e profissionalizante desse público alvo, o que demonstra um retrocesso em termo de concepção à formação profissional e consequentemente uma menor perspectiva de vida autônoma às pessoas com deficiência.

Além disso, o retorno à guerra após as eleições gerais de 1992 (CARVALHO 2002; PEARCE 2017) dificultava amplamente a realização das tarefas preliminares à implementação do ensino especial no território angolano, assim como ampliavam o quantitativo de pessoas com deficiência vítimas desse conflito. A necessidade e urgência de enfrentar esses obstáculos conduziram o governo angolano a recorrer a parcerias com ONGs e Organismos Internacionais (MATOS, 1998). Numa análise mais específica dos países doadores, em especial Norte-Sul, os autores Degnbol e Engberg (2003) ressaltam que as consequências do fim da Guerra Fria para a ajuda externa gerou diminuição no número de países doadores e aumento no número de pretendentes às doações, adicionando pressão nos recursos limitados voltados à cooperação para o desenvolvimento; perda de importância dos interesses políticos relacionados à segurança nacional, abrindo com isso possibilidades para reduções orçamentárias e críticas à ajuda externa; bem como aumento de conflitos nacionais e étnicos, pressionando o financiamento para operações de paz, alívio emergencial e ajuda humanitária. 
Caberia aqui refletir se as políticas educacionais tenderiam a sofrer modificações na sua estrutura organizacional diante desse novo referencial oriundo dos acordos internacionais. Ou ainda, quais seriam os rumos conceituais e atitudinais das políticas voltadas ao ensino especial, a partir dessas influências externas? Seriam elas importantes para a realidade de Angola? Como essa internacionalização das políticas de educação especial foram interpretadas pelo governo angolano?

Segundo Comaroff e Comaroff (2013), o que acontece agora é que, no alvorecer da expansão de modelos liberalizados de mercado, no aperto da integração global fiscal e na globalização da divisão do trabalho, existem poucos lugares que escapam dos efeitos da produção capitalista e de suas formas culturais, embora as maneiras efetivas pelas quais eles tomem forma em diferentes lugares variem de acordo com as condições locais históricas e sociais, e com a localização em um mapa global geopolítico.

Uma das primeiras consequências dessa abertura internacional à Educação Especial em Angola caracterizou-se no encontro Nacional sobre A Educação para Todos em Luanda, realizado pelo Departamento Nacional para a Educação Especial em 1991. O encontro foi mediado pelo Fundo das Nações Unidas para a InfânciaUNICEF e pelo Programa das Nações Unidas para o Desenvolvimento-PNUD; ambos fundamentados nas recomendações da Conferência Mundial de Educação para Todos $^{3}$ ocorrida em 1990 em Jomtien/Tailândia (MBEMBA, 1998).

$O$ resultado desse encontro reconheceu as realidades de diferentes países e possibilitou o princípio de novas reflexões acerca do Ensino Especial em Angola. Dentre as mudanças e ações realizadas pelo Departamento Nacional para a Educação Especial, encontra-se a nomeação de chefes de seção para a área de educação especial em todas as delegações provinciais de educação do país, que visou incentivar os gestores e profissionais da educação a ampliarem o ensino especial em todas as províncias (MBEMBA, 1998; ANGOLA, 2006). Essas nomeações favoreceram a organização e a sensibilização, em nível nacional, dos gestores e profissionais envolvidos com a temática das pessoas com

\footnotetext{
${ }^{3}$ Declaração Mundial sobre Educação para Todos (1990). Aprovada pela Conferência Mundial sobre Educação para Todos Jomtien, Tailândia - 5 a 9 de março de 1990.
} 
deficiência,mesmo que ainda de forma incipiente e sem recursos específicos para investirem na formação e nos materiais necessários à atuação dos profissionais.

Em decorrência destes acontecimentos, o governo angolano alia-se cada vez mais às perspectivas e experiências de outros países, no que concerne a configuração do ensino especial e ratifica no ano de 1994 a sua participação na Conferência Mundial sobre Necessidades Educativas Especiais, por meio da Declaração de Salamanca ${ }^{4}$, ocorrida na Espanha nesse mesmo ano (ANGOLA, 2006, 2015; SALAMANCA, 1994). Esse documento internacional faz uma análise crítica sobre os aspectos segregacionistas e discriminatórios da estrutura organizacional estabelecida nas escolas especiais e nas classes especiais, ao considerar que essas não favoreciam um ambiente adequado ao processo de ensino-aprendizagem aos estudantes com deficiência, por excluírem os mesmos do processo de ensino das escolas regulares junto aos demais estudantes. Entretanto, considera que as escolas especiais são necessárias em raros casos, quando as escolas comuns não conseguissem oferecer um atendimento satisfatório à aprendizagem desse públicoalvo.

Como resposta a essa influência internacional, instaurada pela adesão de Angola à perspectiva da Declaração de Salamanca, implementa-se no ano de 1994 o projeto intitulado Promoção de Oportunidades Educativas para a Reabilitação das Crianças Vulneráveis ${ }^{5}$, o qual inseriu em nível nacional, o conceito e ações de 'integração de crianças com necessidades educativas especiais' nas escolas de ensino regular e nas salas especiais (ANGOLA, 2006).

Nesse momento, é possível visualizar a influência significativa movida pela Declaração de Salamanca, uma vez que o Departamento de Educação Especial inseriu na proposta do projeto escolas de ensino regular e salas integradas. Ou seja, para além das salas especiais e escolas especiais, o projeto buscava sensibilizar os professores e gestores escolares sobre a 'integração' dos alunos com 'necessidades

4 Como resultado da Conferência Mundial sobre Necessidades Educacionais Especiais, realizada entre 7 e 10 de junho de 1994, na cidade espanhola de Salamanca. A Declaração de Salamanca trata de princípios, políticas e práticas na área das necessidades educativas especiais.

5 Descrito por Projeto 534/Ang/10. As propostas de ação de Portugal-UNESCO permitiram o financiamento pelo governo da Itália para implementação desse projeto. Essa proposta foi considerada a primeira cooperação técnica na área da Educação Especial a ser implementada em Angola (ANGOLA, 2006). 
educativas especiais' no ensino regular junto com os demais alunos, por meio das 'salas integradas'. Contudo, isso não excluía, evidentemente, o atendimento das escolas especiais e salas especiais. Outra expressiva alteração ocorreu no ano de 1995, com a substituição do Departamento Nacional para a Educação Especial, pela criação da Direção Nacional para a Educação Especial, com a finalidade de oferecer à modalidade uma maior autonomia administrativa e capacidade técnica para confrontar-se com os novos desafios colocados pela adesão à referida Declaração (ANGOLA, 2006).

Apesar do Projeto Promoção de Oportunidades Educativas para a Reabilitação das Crianças Vulneráveis ter sido elaborado em nível nacional, a sua implementação ocorreu apenas nas regiões que não estavam sendo afetadas pela guerra civil ${ }^{6}$ (MBEMBA, 1998). Muitas províncias e comunas passaram a ser arena de uma guerra devastadora, que levou à morte e a migração de muitas pessoas, incluindo profissionais da área educacional e à destruição de estruturas escolares, ampliando o contexto de exclusão social e o sucateamento dos equipamentos e materiais didáticos escolares (PEARCE, 2017).

As províncias atingidas pela guerra tinham maiores dificuldades (recursos humanos e econômicos) de gerir suas estratégias de ensino. Contudo, muitas ações unilaterais e de iniciativas de alguns profissionais da educação tomavam corpo e conspiravam para a implementação dos serviços na área da Educação Especial, mesmo sendo essas atuações pontuais e com limitados recursos e apoio técnico específico ao tema que garantisse a qualidade e o início dos atendimentos educacionais na comunidade.

Numa análise mais ampla, os serviços de Educação Especial durante o período de guerra civil na II República foram extremamente limitados. Matos (1998) ressalta um levantamento realizado no ano de 1998, no qual foram identificadas mais de 5.000 crianças com deficiências em todo país, considerando a dificuldade de comunicação e acesso devido à guerra. Entretanto, segundo a autora, apenas aproximadamente 500 crianças com deficiência recebiam atendimento educacional, distribuídos em quatro escolas especiais, duas localizadas na Província de Luanda, uma em Huíla e

\footnotetext{
${ }^{6}$ A primeira etapa do projeto contemplou as províncias de Luanda, Benguela e Lubango, incluindo sensibilização das autoridades locais e da comunidade, seleção e diagnóstico e colocação de próteses às crianças com deficiência auditivas, confecção de carteiras, compra de livros e lapiseiras.
} 
uma em Benguela, assim como serviços das salas especiais localizadas em 5 escolas regulares de Luanda e 1 escola regular da Huíla. Olinda Matos relata que as dificuldades eram tão intensas que não foi possível providenciar qualquer tipo de serviço às 4.500 crianças que haviam sidos identificadas, como consequência elas ficavam em casa sem receber atendimento, ou frequentavam as aulas das escolas regulares onde eram segregadas, uma vez que as escolas não tinham formação adequada para compreender o processo de inclusão dessas crianças (MATOS, 1998). Logo havia uma distância considerável entre a proposta de ensino que se queria aos estudantes sujeitos da educação especial e a realidade do momento histórico vivenciado em meio a tantos obstáculos.

\section{Educação Especial em tempos de paz}

O calar das armas no ano de 2002 foi a principal conquista da paz, uma vez que para se pensar em desenvolvimento era necessário pensar na existência humana, e essa só foi possível sem ação armada, sem guerra (CARVALHO, 2013). A consolidação da reconciliação nacional facilitou e incentivou a expansão do ensino especial à todas as províncias do país (ANGOLA, 2015). A partir da instauração da paz, o governo angolano investe expressivamente na elaboração e aprovação de documentos e legislações voltados ao ensino especial, os quais passam a embasar e orientar os investimentos e a ampliação dos atendimentos especializados aos educandos sujeitos da Educação Especial.

O gráfico 01 demonstra o quantitativo de alunos sujeitos da Educação Especial matriculados no sistema de ensino angolano nos anos de 2001 a 2014, essa evidencia traz significativas mudanças ao ensino especial e demarca o princípio de novas perspectivas educacionais para atender a constante demanda oriunda de um processo histórico de exclusão.

Gráfico 01- Evolução de matrículas dos alunos sujeitos da Educação Especial de 2001 a 2014 


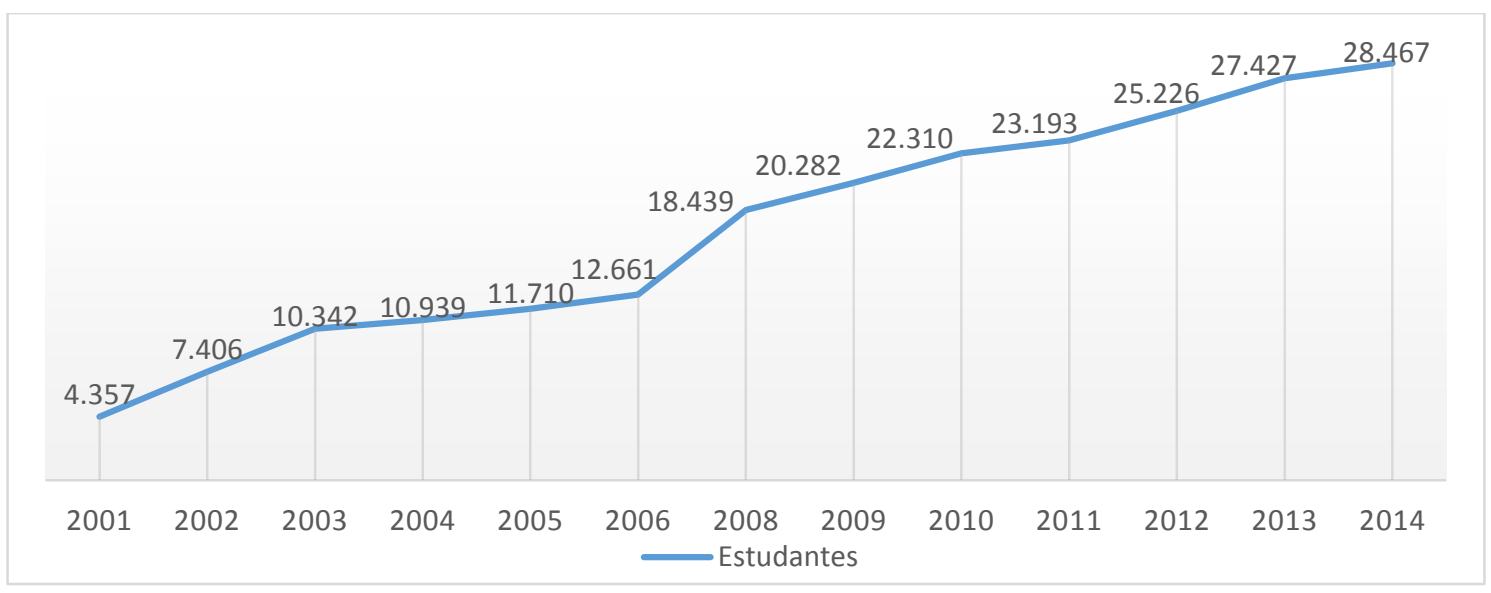

Fonte: Elaboração própria com base em ANGOLA 2006 e 2015.

No ano de 2014 houve o registro de 28.467 alunos sujeitos da Educação Especial $^{7}$ matriculados em 775 escolas 'regulares/inclusivas' e 20 escolas especiais em todo o país. As províncias de Cabinda, Malanje e Uíge não possuem Escolas Especiais na sua estrutura educacional, já as províncias de Benguela e Luanda possuem respectivamente 3 e 4 escolas especiais. As demais regiões registram 1 escola especial por província. Vale recordar que no ano de 1998 havia o registro de apenas 500 alunos contemplados nos atendimentos do ensino especial, já o gráfico 01 demonstra numa escala crescente o registro de 7.406 alunos matriculados no ano de 2002, posteriormente em 2006 o número de 12.661 alunos, e em 2014 o índice atinge o quantitativo de 28.467 alunos. Logo, nos doze anos do pós-guerra (20022014) verificou-se o aumento expressivo de $284 \%$ dos alunos sujeitos da Educação Especial matriculados no Sistema de Ensino angolano, o que corresponde a um aumento médio da ordem dos $11,9 \%$ ao ano.

Essas análises se basearam nos dados quantitativos, legislativos e de políticas sociais e das práticas voltadas ao ensino especial, neste momento não entramos no mérito de uma análise mais profunda no que se refere à avaliação subjetiva e de qualidade oferecida por esse ensino. Contudo, é admissível considerar os indícios positivos oriundos desse processo, enquanto reconhecimento de direitos e capacidade para efetivá-los se comparado à invisibilidade social a que foram

\footnotetext{
${ }^{7}$ Considerar-se-á, nesse período, por "escolas regulares/inclusivas" as escolas do sistema geral de ensino angolano que oferecem acesso à aprendizagem aos alunos com necessidades educativas especiais. Esse acesso se estabelece por meio das salas inclusivas, onde os alunos com e sem necessidades educativas especiais frequentam a mesma turma.
} 
submetidas às pessoas com deficiência durante o período colonial e nos anos da guerra civil.

Outro aspecto importante na ampliação das ações em Educação Especial foi a criação do Instituto Nacional para a Educação Especial - INEE (ANGOLA, 2003c), em substituição da Direção Nacional para a Educação Especial. Os reflexos dessa modificação demonstram uma mudança que vai além da ordem burocrática, ao considerar o ganho do status administrativo com autonomia financeira para o ensino especial, vinculada diretamente ao Ministério das Finanças. Essa mudança incentivou a gestão de projetos e orientações sobre o ensino especial às escolas comuns e escolas especiais. Essa alteração também vai impulsionar a cooperação técnica SulSul no âmbito da formação de professores e elaboração de documentos, como será abordado mais a frente.

Contudo, até o ano de 2006 nem todas as províncias tiveram os mesmos investimentos na área educacional, devido principalmente às consequências da guerra civil e aos reflexos advindos da desigualdade social e econômica do país. Dentre as províncias que conseguiram implementar efetivamente os atendimentos de Educação Especial estão Luanda, Benguela e Huíla (as três províncias mais desenvolvidas economicamente e com maior representatividade demográfica); o segundo grupo caracterizado por apresentar menos condições de implementação inclui as províncias da Lunda Sul, Namibe, Bengo e Kuando Kubango; já no terceiro grupo, caracterizado pelo incipiente desenvolvimento na área da Educação Especial, estão as províncias de Cabinda, Zaire, Uíge, Kwanza Norte, Kwanza Sul, Malange, Lunda Norte, Huambo, Bié, Moxico e Cunene (ANGOLA, 2006, 2015). A partir desses dados é possível constatar que até ao ano de 2006 a maioria das províncias demonstravam ampla dificuldade para implementar e desenvolver a Educação Especial. Logo, mesmo com o aumento no índice de matrículas registrados nesse período, fica evidente que a maioria dos alunos com deficiência permaneciam excluídos do sistema de ensino e/ou não tinham atendimentos adequados para suas especificidades de aprendizagem.

Para Barnes (2013), a crise do capitalismo e a falência de Estado de bem-estar social coloca em questão os direitos das pessoas com deficiência porque dificulta a aplicabilidade dos seus direitos, uma vez que enfraquece economicamente os 
Estados. O reconhecimento por meio das legislações e documentos internacionais que em muitos aspectos ampliam a concepção por extensão de direitos das pessoas com deficiência ocorrem em um ambiente de redução do papel do Estado. Na prática, por mais que se fortaleçam os normativos e legislações oficiais, o grande desafio é enfrentar uma concepção de Estado que passa a destinar irrisórios investimentos orçamentários para os assuntos voltados a tema sobre a deficiência. Se às dificuldades de inclusão educacional acrescermos a estigmatização social de que são alvo as pessoas com deficiência na sociedade angolana (CARVALHO 2008), entenderemos quão sinuoso é o percurso destes sujeitos no processo de integração e inclusão social em Angola.

Em tese, pode-se inferir que de 2001 a 2014 (gráfico 01) existiram investimentos econômicos e administrativos em Angola que impulsionaram a ampliação do acesso à educação dos alunos da Educação Especial que não foram registrados nos períodos históricos anteriores. Esse salto quantitativo no índice de matrículas nos períodos mencionados corrobora em paralelo com alguns fatores sociais importantes que incluem os já mencionados, como o fim da guerra civil, a construção e aumento do número de escolas em todo o país, a inserção e aprovação de políticas públicas geridas pelo INEE/MED ${ }^{8}$ e também a influência advinda da abertura social e a parceria com as agências das Nações Unidas como UNESCO e UNICEF, além de cooperações advindas do chamado "sul global", incluindo Brasil, Rússia e Cuba (ANGOLA, 2006; 2014). Segundo Kabunda (2011), a cooperação Sul-Sul nasceu em plena Guerra Fria com o intuito de transformar o sistema internacional por meio da necessidade de segurança e da busca pelo fortalecimento da independência, do desenvolvimento econômico e social por parte dos países em desenvolvimento. No âmbito da Educação Especial, o Ministério da Educação de Angola construiu a partir de 2007 projetos de cooperação Sul-Sul, dos quais mencionaremos a cooperação bilateral entre Angola e Brasil. Essa cooperação foi estimulada pela ratificação por ambos os países de documentos internacionais, com a vertente em práticas educacionais inclusivas. Entre 2007 a 2014, a referida cooperação proporcionou

\footnotetext{
${ }^{8}$ Aprovação do Decreto Presidencial n.․ 237/2011, 30 de agosto que cria a Política para Pessoa com Deficiência; Decreto Presidencial no 20/2011 de 18 de janeiro que cria o Estatuto da Modalidade da Educação Especial; Plano de Acção da Década Africana das Pessoas Portadoras de Deficiência (20102019).
} 
cursos de capacitação aos docentes, produção de material pedagógico, além do apoio e criação de estruturas nas instituições escolares para educação inclusiva. Os cursos de capacitação oferecidos na área do ensino especial contemplaram a formação de 427 professores/as em todo território Nacional, esses professores/as tornaram-se multiplicadores da formação em suas províncias, o que possibilitou a capacitação de mais 1668 professores/as até o ano de 2014 nos temas vinculados ao ensino especial (ANGOLA, 2017).

Os cursos de capacitação foram iniciativas pontuais para inserir as temáticas voltadas ao ensino especial e com isso sensibilizar os docentes sobre a perspectiva da educação inclusiva. Diante dos acordos internacionais assumidos, o governo angolano ratifica a Convenção sobre os Direitos das Pessoas com Deficiência no dia 19 de maio de 2014 e adota oficialmente o compromisso de assegurar às pessoas com deficiência o acesso a um sistema social e educacional inclusivo.

Segundo Barnes (2013), a convenção da ONU (2006) não é um modelo social da deficiência, por mais que possa ser considerada um exemplo de politização a partir de um entendimento sociopolítico que supera o foco da deficiência concebida de forma individualizada, no qual o impedimento do indivíduo é a causa da deficiência. Para o autor a deficiência entendida numa perspectiva social e politizada seria considerar que as pessoas são deficientes devido à sociedade e é essa que deve se modificar para aceitar a realidade da diversidade humana.

Dessa forma, a deficiência entendida na abordagem social busca o afastamento do fatalismo biológico e religioso e gera possibilidades que favorecem 0 desenvolvimento do indivíduo, despindo-se de preconceito e instituindo práticas de não exclusão. Para Tunes e Pedrosa (2011), a exclusão é social e historicamente condicionada e está configurada dentro de ações, vínculos, interações e retroações que não estão isoladas no mundo e fazem parte de uma vida de relação. Sendo assim é no âmbito da vida em relação que se encontram caminhos para compreender 0 fenômeno da exclusão social.

A partir da abertura política retratada em tempos de paz foi possível perceber a inserção de Angola no cenário mundial acerca da discussão dos temas relativos à pessoa com deficiência, incluindo a ratificação da Convenção da ONU (2006) em 2014 e a adesão ao Protocolo da União Africana (CUA, 2009) ao Plano de Acção da Década 
Africana das Pessoas com Deficiência (2010- 2019). Os encontros nacionais sobre Educação Especial realizados pelo INEE em 2011 e 2014 ressaltaram os avanços do ensino especial e o aumento do índice de alunos nas escolas comuns e escolas especiais. Contudo, inúmeras dificuldades são constatadas na implementação de uma proposta voltada à inclusão escolar, dentre as quais cita-se: as barreiras físicas, atitudinais e de comunicação que impossibilitam a plena participação dos alunos da educação especial nas atividades escolares e sociais; a carência de preparação técnica e profissional dos agentes e agencias educativas incluindo escola, família, comunidade, professores, especialistas e a insuficiência na prestação dos serviços de apoio aos alunos da educação especial nos diferentes contextos de atenção educativa (ANGOLA, 2017).

Destacadamente, entre os anos de 2015 e 2016 foi desenvolvido a cooperação entre Angola e Brasil que contou com a consultoria técnica de profissionais brasileiros na elaboração do Projeto intitulado Política nacional de educação especial orientada para a inclusão escolar ${ }^{9}$. O produto dessa cooperação resultou na aprovação oficial da Política Nacional de Educação Especial por meio do Decreto Lei 187 no ano de $2017^{10}$ e passou a orientar o ensino especial em Angola numa proposta de educação inclusiva baseada na Convenção da ONU (2006) e na experiência vivenciada pelo Brasil por meio da sua própria Política de Educação Especial ${ }^{11}$ implementada no Brasil em 2008 pelo Ministério da Educação, na qual trouxe significativas mudanças sobre a inclusão social das pessoas com deficiência em âmbito nacional.

Em termos legais a aprovação da nova Lei de Bases do Sistema de Educação/LBSE de 2016 revelou-se como o primeiro documento educacional geral a considerar a Educação Especial como modalidade diferenciada, transversal e que perpassa todos os Subsistemas de ensino. Isso demarca uma significativa conquista institucional a área do ensino especial numa perspectiva inclusiva, por considerar que

\footnotetext{
${ }^{9}$ Projeto Cooperação entre INEE (Angola), UNICEF (Angola) e Instituto Rodrigo Mendes (Brasil), que contou com a consultoria técnica de profissionais brasileiros na elaboração do documento técnico Política nacional de educação especial orientada para a inclusão escolar, o qual pautou os fundamentos teórico e prático na concepção da Convenção da ONU de 2006 e na Política Nacional de Educação Especial na perspectiva da educação inclusiva de 2008 do Brasil.

10 Decreto Presidencial que aprova a Política Nacional de Educação Especial Orientada para a Inclusão Escolar em 2017.

11 Política Nacional de Educação Especial na perspectiva da educação inclusiva de 2008 do Brasil.
} 
todos os alunos com e sem deficiência usufruam do mesmo local de aprendizagem da educação pré-escolar ao ensino técnico-profissional e superior. Entretanto, o artigo 85ํํㅁ LBSE/2016, prevê também que o ensino especial pode ser ministrado em salas especializadas de outras instituições devidamente autorizadas. Dessa maneira o ensino especial para além das escolas regulares, mantem a estrutura das escolas especiais e salas especiais.

Contudo, a grande mudança de paradigma encontra-se na proposta da Política Nacional - Decreto 186/2017 de estabelecer a ressignificação das escolas especiais ao propor que as mesmas passem a atuar como "Núcleos de Apoio à Inclusão - NAls" (ANGOLA, 2017 - Decreto 187 item VI). Essa proposta ambiciona que, paulatinamente, todos os alunos da Educação Especial deverão ser incluídos nas escolas regulares de ensino, e que as escolas especiais terão uma nova proposta de atuação que contemplará o suporte técnico e de formação às escolas regulares de ensino e não mais como uma escola específica para esse público alvo da Educação Especial, o que levaria no decorrer desse processo a eliminação da perspectiva segregacionista das escolas especiais e daria as mesmas o status de Núcleo de Apoio ao processo de inclusão escolar.

\section{Considerações finais}

A consonância da nova LBSE/2016 (ANGOLA, 2016), o Decreto 187/2017 (ANGOLA, 2017) ratificam a perspectiva social da Educação Especial contemplada pela Convenção dos Direitos das pessoas com deficiência da ONU (2006) e do Plano de Acção da Década Africana das Pessoas com Deficiência (CUA, 2009), bem como revogam toda legislação que contrarie essa concepção. Com isso, a educação segregacionista evidenciada por meio das Escolas Especiais e na invisibilidade dos sujeitos da Educação Especial na sociedade angolana passa a ser questionada e ter novas propostas de atuação direcionadas pelo INEE.

Muitos são os questionamentos e ponderações advindas desse arco institucional de inclusão escolar. Não temos aqui a pretensão de inferir o que é certo ou errado, ou mesmo considerar que existiria um único caminho para garantir o direito das pessoas com deficiência em Angola. Todavia, cabe refletir sobre o que essa Política irá proporcionar à sociedade angolana, em destaque às pessoas com deficiência. Para tanto, muitos serão os 
estudos futuros a partir de uma concepção de inclusão social das pessoas com deficiência, na qual pode-se conjeturar alguns temas ao observatório dessa Política, nas seguintes reflexões:

Que impactos sociais essa mudança de paradigma trará às pessoas com deficiência? Como as famílias irão reagir a perspectiva de inclusão escolar de seus filhos e filhas? Como as escolas especiais farão as mudanças conceituais e estruturais para se transformarem em núcleos de inclusão diante da historicidade da exclusão escolar? Quais serão os desafios orçamentários para implementação da política em âmbito nacional? Terá o governo angolano prioridade no Orçamento Geral do Estado (OGE) para investir na Educação Especial a partir dessa proposta assumida pelo próprio governo? Que impactos culturais e sociais a política de inclusão pode ter na compreensão da sociedade sobre a deficiência? Qual a opinião da sociedade angolana na proposta de inclusão escolar de alunos com deficiência no sistema de ensino regular? Como as pessoas com deficiência participam desse processo de implementação da política e qual sua opinião sobre o tema? Quais são/serão os desafios educacionais para implementação da política na voz dos professores e professoras do ensino geral? Qual o envolvimento das ONGs na implementação da Política de Inclusão, ou então qual será os desafios que as mesmas irão encontrar?

Resgatamos ainda a memória da primeira proposta de Educação às pessoas com deficiência de 1977, a qual foi estabelecida por meio da compreensão de que os alunos com deficiência pudessem usufruir do sistema geral de ensino angolano junto com os alunos sem deficiência, assim como propôs a criação de espaços específicos para o atendimento profissionalizante desses alunos. À época do pós-independência pareceu ser uma utopia devido às condições sociais já mencionadas com o conflito armado. Hoje, 41 anos após a primeira proposta de ensino, vemos se ampliar o reconhecimento dos direitos às pessoas com deficiência, na sua mais significativa simbologia e concretude por meio da atual LBSE/2016, e da Política nacional de educação especial orientada para a inclusão escolar - Decreto 187/2017) e dos dados referentes ao número de escolas e matrículas de alunos com deficiência no sistema de ensino. Isso nos instiga a conjecturar que talvez 0 tempo passado não tenha oferecido respostas satisfatórias quanto a exclusão social e educacional das pessoas com deficiência em Angola, mas quem sabe o tempo vindouro 
abone a esperada mudança de viabilizar nada mais, nada menos do que aquilo que lhes é direito e que Ihes foi negado no decorrer da história.

\section{Referências}

ANGOLA, República de. Assembleia do Povo. Constituição da República Popular de Angola. Luanda, 1975.

ANGOLA, República de. Ministério da Educação. Circular no 56 de 19 de setembro de 1979. Luanda: Ministério da Educação. Luanda, 1979.

ANGOLA, República de. Decreto-lei ㄲo 40. Estatuto Orgânico do Ministério da Educação. Luanda, Presidência da República, 1981.

ANGOLA, República de. Lei no 23/92, de 16 de setembro de 1992. Lei de Revisão Constitucional. Luanda, 1992.

ANGOLA, República de. Ministério da Educação. Relatório de atividades. Luanda, 2003a.

ANGOLA, República de. Lei oㅡ 13/01, de 331 de dezembro de 2001. Estabelece a Lei de Base do Sistema de Educação. Luanda, 2003b.

ANGOLA, República de. Decreto Lei no 07/03, de 17 de junho de 2003. Lei Orgânica do INEE. Ministério da Educação. Diário da República, Órgão oficial da República de Angola. I Série № 47, 2003.

ANGOLA, República de. Ministério da Educação. Instituto Nacional para a Educação Especial (INEE). Plano Estratégico de Desenvolvimento da Educação Especial em Angola 2007-2015. Instituto Nacional para a Educação Especial, Luanda, 2006.

ANGOLA, República de. Constituição da República Popular de Angola, 2010.

ANGOLA, República de. Ministério da Educação. Relatório de monitorização sobre Educação para Todos. Luanda, 2014.

ANGOLA, República de. Ministério da Educação. Instituto Nacional para a Educação Especial (INEE). Projecto da Política Nacional de Educação Especial Orientada para a Inclusão Escolar. Ministério da Educação. Luanda, 2015.

ANGOLA, República de. Ministério da Educação. Instituto Nacional para a Educação Especial (INEE). Política Nacional de Educação Especial Orientada para a Inclusão Escolar. Luanda, 2015.

ANGOLA, República de. Lei №17/16, de 07 de outubro de 2016. Lei de Bases do Sistema de Educação LBSE. Diário da República, Órgão oficial da República de Angola. I Série, № 170, 2016. 
ANGOLA, República de. Decreto Presidencial n. 187/17, de 16 de agosto de 2017. Política Nacional de Educação Especial Orientada para a Inclusão Escolar. Diário da República, Órgão oficial da República de Angola. I Série, № 140, Luanda, 2017.

BARNES, Colin. Deficiência e Políticas sociais. Revista SER Social, Brasília, v.15, n.32, p. 237-251, jan/jun, 2013.

BEAUD, Stéphane e WEBER, Florence. Guia para a pesquisa de campo: produzir e analisar dados etnográficos. Petrópolis, RJ: Vozes, 2007.

CARVALHO, Paulo de. Angola, quanto tempo falta para amanhã? Oeiras, Celta Editora, 2002

CARVALHO, Paulo de. Exclusão social em Angola. $O$ caso dos deficientes físicos de Luanda, Luanda, Kilombelombe, 2008.

CARVALHO, Paulo de. $O$ calar das armas foi a principal conquista da paz. Revista Angolana de Sociologia p. 123-129, 2012.

CARVALHO FILHO, Silvio de Almeida. Angola: história, nação e literatura (19751985). Curitiba: Editora Prismas, 2016.

CELLARD, André. A análise documental. In.: A pesquisa qualitativa: enfoques epistemológicos e metodológicos. Petrópolis, RJ: Vozes, 2008.

COMAROFF Jean \& COMAROFF. John L. Teoria desde El Sur: o como los países centrales evolucionan hacia áfrica. Buenos Aires, Ed. Siglo Veintiuno, 2013.

CUA. COMISSÃO DA UNIÃO AFRICANA. Plano de Acção da Década Africana das Pessoas com Deficiência (2010- 2019). Disponível em: https://au.int/sites/default/files/pages/32900-filecpoa_handbook._audp._portuguese_-_copy.pdf. Acesso em: 4 fev. 2016.

DEGNBOL-MARTINUSSEN, John; ENGBERG-PEDERSEN, Poul. Aid: Understanding International Development Cooperation. Tradução de Marie Bille. London, New York: Zed Books Ltd, 2003.

FREUDENTHAL, Aida. Construindo o passado angolano: as fontes e a sua interpretação. In: II SEMINÁRIO INTERNACIONAL SOBRE A HISTÓRIA DE ANGOLA, Luanda, 4 a 9 agosto de 1997. Anais: Comissão Nacional para as Comemorações dos Descobrimentos Portugueses. Jill R. Dias, Rosa Cruz e Silva, 2000. p. 429-442.

JACCOUD, Mylène e MAYER, Robert. A observação direta e a pesquisa qualitativa. In.: A pesquisa qualitativa: enfoques epistemológicos e metodológicos. Petrópolis, RJ: Vozes, 2008. 
KABUNDA, Mbuyi. (Coord). África y la cooperación com el Sur desde el Sur. Casa África, 2011.

LIBERATO, Ermelinda. Avanços e retrocessos da educação em Angola. Revista Brasileira de Educação, v.19, n.59, p. 1003-1031, out-dez. 2014.

MATOS, Olinda Josefa de. A educação especial em Angola. In. Necessidades Educativas Especiais em Angola. Dakar-Senegal: Ibrahima Ndiaye, UNESCO, 1998.

MBEMBA, Valeriano Valodia. Angola e Unesco. In. Necessidades Educativas Especiais em Angola. Dakar-Senegal: Ibrahima Ndiaye, UNESCO, 1998.

NETO, Maria da Conceição. In Town and Out of Town: A Social History of Huambo (Angola) 1902-1961. Thesis submitted for the degree of PhD in History. PhD Thesis, SOAS, University of London, 2012.

NGULUVE, Alberto Kapitango. Educação Angolana: Políticas de Reformas do Sistema Educacional. São Paulo: Biscalchin Editor, 2010.

ONU. ORGANIZAÇÃO DAS NAÇÕES UNIDAS. Convenção sobre os direitos das pessoas com deficiência. Resolução A/61/106, 13/12/06. Nova York: Nações Unidas, 2006.

PANTOJA, Selma Alves. Historiografia africana e os ventos sul: desenvolvimento e história transversos. Revista de História. Rio de Janeiro, n. 08, p. 46-70, dez. 2016.

PAXE, Isaac Pedro Vieira. Políticas educacionais em Angola: desafios do direito à Educação. Tese (Doutorado em Educação). Universidade de São Paulo, p. 217, 2014.

PEARCE, Justin. A guerra civil em Angola 1975-2002. Lisboa: Tinta-da-china, 2017.

TUNES, E.; PEDROSA, L. P. O silêncio ou a profanação do outro? In. TUNES, E. (Org.) Sem escola, sem documento. E-papers Serviços Editoriais Ltda, p.15-30, 2011.

UNESCO. Declaração de Salamanca. Sobre Princípios, Políticas e Práticas na Área das Necessidades Educativas Especiais. Disponível em: http://portal.mec.gov.br/seesp/arquivos/pdf/salamanca.pdf. Acesso em: 23 dez. 2016.

VIEIRA, Laurindo. Angola: A Dimensão Ideológica da Educação 1075 - 1992. 1. ed. Luanda: Editora Nzila, 2007.

ZAU, Filipe. Angola: trilhos para o desenvolvimento. Universidade Aberta Lisboa, 2002.

ZAU, Filipe. Educação em Angola: novos trilhos para o desenvolvimento. Luanda: Movilivros, 2009. 


\section{Correspondência}

Daniela Antonello Lobo D'avila - Universidade de Brasília. UnB - Brasília. CEP: 70910-900. Brasília, Distrito Federal, Brasil.

\section{(c) (i) (3)}

This work is licensed under a Creative Commons Attribution-NonCommercial 4.0 International (CC BY-NC 4.0) 